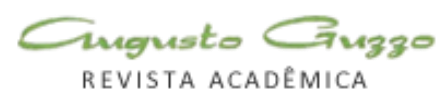

\title{
Eros e Psiquê na organização: uma abordagem multidisciplinar
}

\author{
Nanci Geroldo \\ Recebido em: 07/04/2013. Aprovado em: 21/04/2013. Disponibilizado em: 26/06/2013 \\ 1. Nanci Geroldo é Doutora e Mestra em Letras pela Universidade de São Paulo. Professora pesquisadora da Faculdade ENIAC. \\ E da Faculdade Anchieta/SP. Parecerista membro do corpo editorial da revista acadêmica Augusto Guzzo e ENIAC Pesquisa.
}

\section{Resumo}

Este artigo "Eros, psiquê na organização: Uma abordagem multidisciplinar" é fruto da reflexão para ministrar aulas sobre análise de texto e suas possíveis abordagens na formação profissional. O objetivo é demonstrar uma possibilidade de realmente qualificar os alunos para o Mercado de trabalho, de acordo com as novas propostas pedagógicas, com base na nterdisciplinaridade.

Palavras-chave: interdisciplinaridade, conhecimento, ensino, aprendizagem.

\begin{abstract}
This article "Eros, psyche in organization: a multidisciplinary approach" is the fruit of reflection to teach classes on analysis of text and its possible approaches in vocational training. The goal is to demonstrate the possibilities of really qualify students for the labor market, in accordance with the new pedagogical proposals, on the basis of the interdisciplinaridade.
\end{abstract}

Keywords: Interdisciplinarity, knowledge, education and learning. 



\section{Introdução}

A interdisciplinaridade pode ser entendida como uma das propostas da não fragmentação do ensino, ou seja, a partir da junção das diversas áreas do conhecimento por meio da pesquisa, ampliamos a visão de mundo do alunado, relacionamos a teoria à prática e formamos profissionais mais capacitados ao mercado de trabalho que se encontra cada vez mais exigente.

A partir do momento que a interdisciplinaridade oferece uma nova postura diante do processo ensinoaprendizagem e da formação do indivíduo, perfazemos uma busca da aplicação do contexto do conhecimento e da pessoa que nele esteja inserida. Trata-se do saber em sua totalidade que, de acordo com Ivani Fazenda (1999), pode ser nomeado como "uma postura interdisciplinar", isto é, a busca, a pesquisa, a inclusão do educando de acordo com as necessidades de sua formação como um todo.

Mediante um texto, seja de qualquer natureza, temos a possibilidade de vários níveis de interpretação e de aplicação da mensagem que ele porta. No entanto, temos de ter em mente que é necessário um prévio conhecimento de mundo, de textos anteriores inseridos direta ou indiretamente para que isso aconteça.

Neste trabalho, diante das inúmeras possibilidades de leitura, optamos pela análise de um poema pessoano e, a partir disso, nos reportamos à mitologia grega quanto à história de Eros e Psiquê, analisamos e aplicamos no ambiente organizacional os quatro trabalhos que esta teve de desenvolver para reconquistar o amor perdido.

O diálogo com outras formas de conhecimento, segundo Fazenda (1999):

Nenhuma forma de conhecimento é em si mesma racional. Tenta, pois, o diálogo com outras formas de conhecimento, deixando-se interpenetrar por elas. Aceita o conhecimento do senso comum como válido, pois é através do cotidiano que damos sentido às nossas vidas. Ampliado através do diálogo com o conhecimento científico, tende a uma dimensão utópica e libertadora, pois permite enriquecer nossa relação com o outro e com o mundo (FAZENDA, 1999:17).

O trabalho interdisciplinar deve apresentar plena integração de conteúdos, ou seja, de uma percepção fragmentária passamos para uma concepção unitária do conhecimento. Devemos levar em conta que o processo ensino-aprendizagem liga-se à educação continuada e deve haver total integração entre os conhecimentos específicos da área e aqueles advindos da informação e da experiência de vida do educando.

\section{Eros, Psiquê e a formação profissional}

A partir dos conhecidos versos de Fernando Pessoa, abordaremos a interdisciplinaridade como fator para melhor compreensão de um texto e sua aplicabilidade no cotidiano do aluno, fornecendo elementos para um amplo aprendizado. Vejamos o texto: 


\begin{tabular}{|l|l|}
\hline Conta a lenda que dormia & Mas cada um cumpre o Destino \\
Uma Princesa encantada & Ela dormindo encantada, \\
A quem só despertaria & Ele buscando-a sem tino \\
Um Infante, que viria & Pelo processo divino \\
De além do muro da estrada. & Que faz existir a estrada. \\
Ele tinha que, tentado, & E, se bem que seja obscuro \\
Vencer o mal e o bem, & Tudo pela estrada fora, \\
Antes que, já libertado, & E falso, ele vem seguro, \\
Deixasse o caminho errado & E vencendo estrada e muro, \\
Por o que à Princesa vem. & Chega onde em sono ela mora, \\
A Princesa Adormecida, & E, inda tonto do que houvera, \\
Se espera, dormindo espera, & À cabeça, em maresia, \\
Sonha em morte a sua vida, & Ergue a mão, e encontra hera, \\
E orna-lhe a fronte esquecida, & E vê que ele mesmo era \\
Verde, uma grinalda de hera. & A Princesa que dormia. \\
Longe o Infante, esforçado, & \\
Sem saber que intuito tem, & \\
Rompe o caminho fadado, & \\
Ele dela é ignorado, & \\
Ela para ele é ninguém & \\
&
\end{tabular}

Ao trabalharmos em sala com os alunos, há a necessidade de, num primeiro momento, falar da importância desse poeta português e de seus escritos literários mesmo que de forma breve. A partir disso, partimos para a interpretação ou interpretações pertinentes ao tema. Uma das propostas é a de colocarmos "princesa" e "príncipe" como a mesma pessoa: "E vê que ele mesmo era / A Princesa que dormia". Qual o sentido desse poema? Qual a busca do príncipe? Que caminho tortuoso é esse? Como aplicar isso à vida de cada um?

Buscamos o conhecimento, mesmo que por caminhos tortuosos. Diariamente somos postos à prova e nos conhecemos melhor, assim como aprendemos a conhecer os outros e a nos reconhecer em outros. A busca por um mundo melhor, uma vida melhor, um cargo, um emprego, um amor. São tantas as buscas que às vezes nos sentimos confusos, atordoados com o que está à nossa volta, titubeantes quanto às decisões que a vida nos exige. É necessário, pois, que o professor oriente seus alunos nessas reflexões e que ouça atentamente as respostas dadas a fim de que o processo de interpretação não se perca e se torne unilateral.

O processo ensino-aprendizagem por meio da interdisciplinaridade ou multidisciplinaridade começa a emergir a 
partir desse texto e percebemos que todos os envolvidos têm a ganhar - alunos $\mathrm{e}$ professores interagem e ampliam seus conhecimentos tornando $\mathrm{O}$ ambiente acadêmico mais dinâmico, também, por terem de pesquisar outros campos que não apenas o de sua área; a instituição também recebe seus louros por executar sua proposta pedagógica de maneira leve e eficiente; os problemas como a (in)disciplina em sala de aula podem ser minimizados bem como o relacionamento entre alunos com os demais integrantes da instituição e da comunidade que a cerca.

Num segundo momento, colocamos a pesquisa sobre "Eros" e "Psiquê". Quem são? O que representam? Eros (Cupido, no panteão romano) era o deus grego do amor. Hesíodo, na sua Teogonia, considera-o filho de Caos, portanto um deus primordial. Além de o descrever como sendo muito belo e irresistível, levando a ignorar o bom senso, atribui-lhe também um papel unificador e coordenador dos elementos, contribuindo para a passagem do caos ao cosmos. Posteriormente foi considerado como um deus olímpico, filho de Afrodite e de Zeus, Hermes ou Ares, conforme as várias versões.

O mito de Psiquê é narrado no livro " $O$ Asno de Ouro", de Apuleio (séc II a.C.), citando-a como uma bela mortal por quem Eros, o deus do amor, se apaixonou. Tão bela que despertou a fúria de Afrodite, deusa da beleza e do amor, mãe de Eros. O pai da jovem, temeroso com o futuro de sua filha, consulta o Oráculo de Delfos, que, induzido por Eros, diz ser o destino dessa jovem casar com um ente monstruoso. Os pais de Psiquê seguem um ritual para o casamento de sua filha, de acordo com as instruções recebidas em Delfos e a levam para uma colina. Zéfiro a conduz até o palácio. Ela, adormecida, nada vê, nada sente até chegar em seu novo lar. Ali, já desperta, sente fome e um banquete lhe é oferecido.
Sua vida se transforma, tinha tudo o que desejava jóias raras, roupas finas, mas jamais poderia ver a face do marido. Quando juntos, ele usava um capuz para esconder sua real identidade e a fez prometer que não usaria de artimanhas para conhecê-lo, pois a abandonaria.

Passado algum tempo, as irmãs de Psiquê vão visitá-la e, cheias de inveja, insistem para que ela veja a face do "monstro" com quem se casou. Curiosa, enquanto seu marido dorme, levanta um candeeiro e vê a face do deus; assustada e ao mesmo tempo feliz com sua sorte, deixa que uma gota de azeite caia no ombro do marido e ele a abandona, furioso, por ter sido traído. O amor está ferido.

Psiquê, então, vaga pelo mundo à procura de uma maneira de reaver seu amor até que chega ao templo de Afrodite, que decide impor uma série de tarefas, esperando que Psiquê delas nunca se desincubisse ou tanto se desgastasse perdendo a beleza.

A jovem aceita os trabalhos e, com o auxílio de outros seres, cumpre um a um; no entanto, ao terminá-los, entra na "zona de conforto" e se esquece de que cuidados extras deveriam ser tomados. Quantas vezes, no ambiente pessoal e profissional, não nos deparamos com situações assim? O melhor é pensar e avaliar o que devemos mudar em nossas atitudes, melhorar em nossos estudos e atentar para o que está por vir. Mesmo que o caminho seja tortuoso.

\section{Os trabalhos de Psiquê e a formação profissional}

Psiquê tem de cumprir quatro tarefas, impostas por Afrodite, para reconquistar o amor de Eros. As exigências são muitas e quase impossíveis de serem cumpridas. A primeira tarefa era a de separar, conforme cada espécie e no decorrer de uma noite, 
uma montanha de diversos tipos de grãos que tinham sido misturados. A princesa começa seu trabalho, mas adormece extremamente cansada com alguns montículos formados. Surgem milhares de formigas que, durante seu sono, separam esses grãos de acordo com sua categoria. Ao acordar, constata que a tarefa havia sido cumprida.

No ambiente de trabalho, encontramos alguns profissionais que, mesmo ocupando altos cargos não conseguem cumprir com todas as tarefas que lhes são atribuídas, seja por imcompetência, falta de preparo ou simplesmente por não saberem trabalhar em equipe. Psiquê se revela um profissional assim, na ânsia de alcançar seu objetivo reconquistar Eros - se esquece da preciosa equipe que a cerca. As formigas fazem o trabalho extenuante e em sincronismo para que a tarefa seja cumprida com eficiência e eficácia.

Percebemos que, embora haja colaboradores ocupando postos não tão altos na escala organizacional, estes se tornam imprescindíveis para que a empresa se torne uma referência no mercado em que atua. Atuar em equipe pode fazer com que os diversos problemas que a empresa tem de resolver dia a dia se tornem mínimos.

No segundo trabalho, Afrodite pede a Psiquê um punhado de lã de ouro que alguns carneiros produziam. A princesa encontra os ferozes animais, que não a deixavam que deles se aproximassem. Ela ouve uma voz surge perto dos juncos na beira do rio e a aconselha a procurar um espinheiro, próximo de onde os carneiros vão beber água. Das pontas dos espinhos, ela recolhe toda a lã que ficara presa e entrega a Afrodite.

Podemos entender que a intuição e a criatividade devem estar presentes no dia a dia de qualquer profissional. Planejamento estratégico e visão ampliada de todas as possibiliades para alcançar os objetivos propostos pela empresa devem fazer parte de um bom profissional. O mercado é feroz, mas há vários recursos a serem utilizados para a obtenção dos resultados esperados, das metas propostas, dos deveres a cumprir.

A terceira tarefa parece, assim como as outras, impossível de ser realizada: Afrodite lhe pede um pouco da pura água do Rio Estige, que nascia duma alta montanha, tão íngreme que era impossível escalar. Levando um frasco numa das mãos, a princesa se depara com um despenhadeiro que se erguia à frente; uma das águias de Zeus surge, toma-lhe o frasco, voa com ela até o alto, e o enche da mais pura água.

Humildade para aprender e senso de observação de como agem os mais experientes no ambiente de trabalho também são importantes para que as tarefas designadas ao profissional sejam cumpridas plenamente. Há momentos em que não se sabe "como" fazer algo; assim, torna-se imperioso o constante aperfeiçoamento, mesmo que apenas pela observação.

A quarta e última tarefa seria a pior de todas: Afrodite pede a Psiquê que, descendo ao Reino dos Mortos, convença Perséfone, esposa de Hades, a lhe entregar um pouco de sua beleza. Perséfone, inimiga de Afrodite, enche uma caixa com sua beleza para Afrodite, mas avisa para que a entregue apenas à mãe de Eros e que não abra a caixa em hipótese alguma. Psiquê está voltando pela estrada e pensa que sua beleza havia se desgastado depois de tantos trabalhos; não resiste e resolve abrir a caixa, caindo em sono profundo, Eros vai ao socorro de sua amada, põe de volta o conteúdo para a caixa, desperta Psiquê e ordena-lhe que entregue a caixa à mãe dele.

Por melhor que seja, um profissional deve saber exatamente quais são suas obrigações dentro de uma empresa: o que parece bom para alguns pode não ser para 
ele. Cumprir metas, alcançar objetivos, auxiliar, trabalhar em equipe são ações esperadas, mas não se deve tomar para si trabalhos que sejam de outros - as surpresas podem não ser tão boas assim.

\section{Considerações Finais}

No processo ensino-aprendizagem, o professor norteia o aluno a descobrir, a construir e a se posicionar frente ao conhecimento. Ninguém o constrói sozinho por ser uma ação contínua de pesquisa e da interação com outrosindivíduos. De acordo com Ivani Fazenda, há cinco princípios básicos para a prática docente interdisciplinar: humildade, espera, respeito, coerência e desapego.

Ao confrontarmos esses princípiios com os trabalhos de Psiquê, notamos que, quanto ao primeiro, há de se ter respeito por aqueles que julgamos menos instruídos ou capacitados, mas que demonstram espírito de equipe; no segundo, a coerência entre o "fazer", o "saber fazer" e a criatividade; no terceiro, a humildade em aprender com os mais experientes e, no último, o desapego àquilo que não nos cabe. A espera está em todos eles: nenhum profissional está pronto para o mercado de uma hora para outra.

Desvendar novos conhecimentos, reconhecer nossas limitações e ter coragem para superá-las fazem do processo de ensino-aprendizagem uma atitude de reciprocidade que conduz à troca e ao diálogo com o mundo que nos cerca.

\section{Referências Bibliográficas}

1. BRUNEL, P. (org). Dicionário de Mitos Literários. Rio de Janeiro: J. Olympio, 1998.

2. FAZENDA, I. Práticas Interdisciplinares na Escola. 6.ed. São Paulo: Cortez, 1999.

3. PESSOA, Fernando. "Eros e Psiquê", disponível em http://www.insite.com.br/ art/pessoa/cancioneiro/182.html, acesso em 06/07/2012, às $14 \mathrm{~h} 45$. 